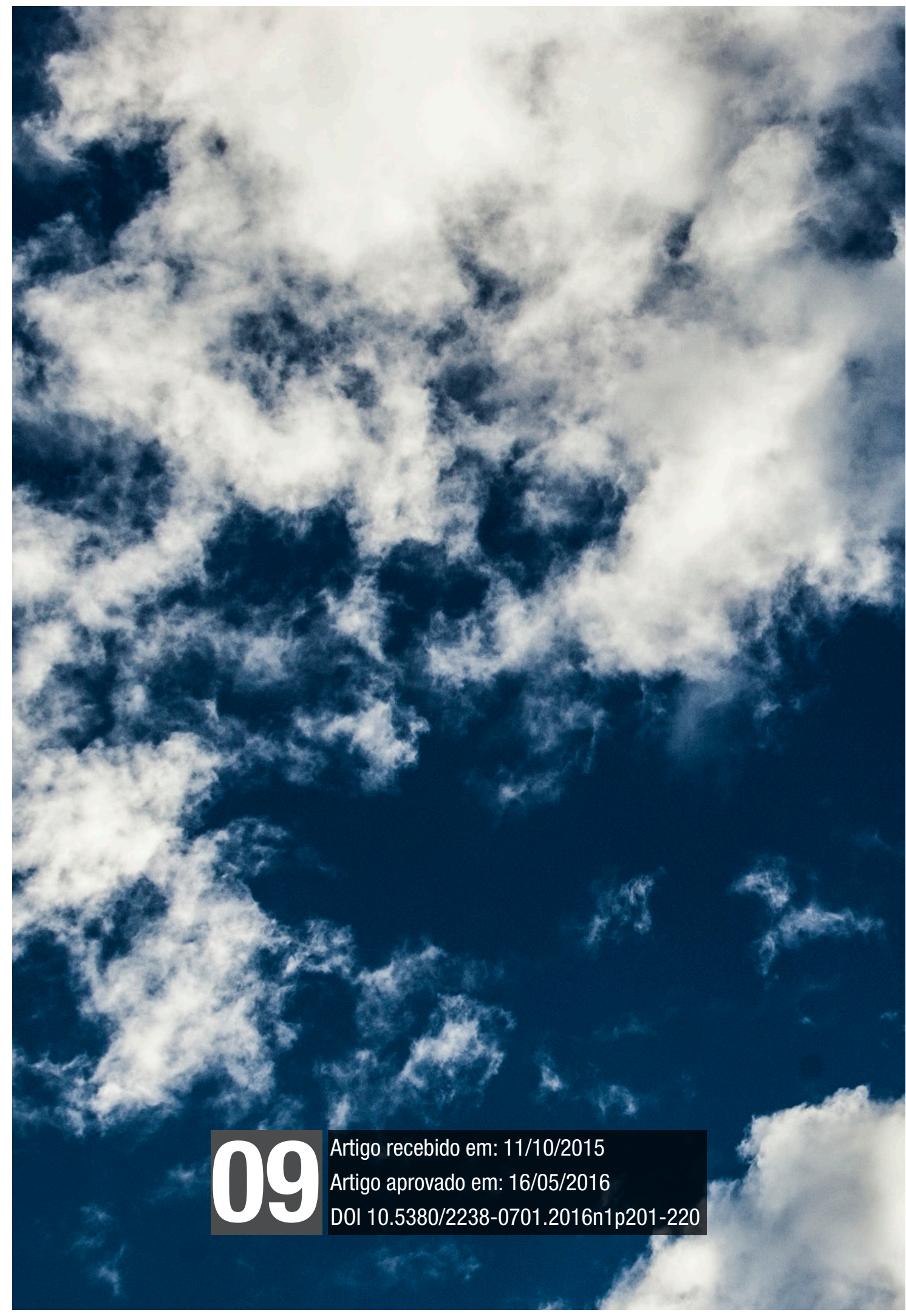


Ciberespaço. Nuvem. Cibercultura.

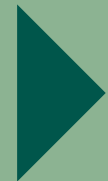




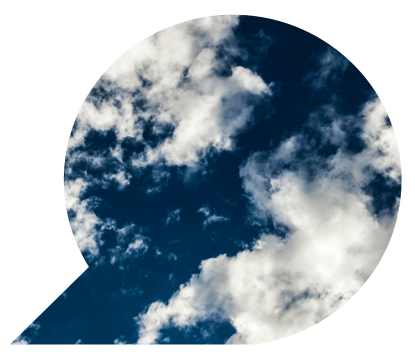

\title{
Onde está o ciberespaço? A metáfora da "nuvem" aplicada aos estudos da cibercultura
}

\author{
Where is the cyberspace? The "cloud" \\ metaphor applied to cyberculture studies \\ ¿Dónde está el ciberespacio? La metáfora \\ de la "nube" aplicada a los estudios de la cibercultura
}

\section{IVAN SATUF *}

Resumo: A noção seminal de ciberespaço presente na obra literária de William Gibson está centrada na dicotomia conexão/desconexão e o desenvolvimento subsequente dos estudos da cibercultura ajudou a reforçar a separação entre on-line (ou virtual) e off-line (ou real). Este artigo questiona a validade desta concepção binária diante do atual cenário social e tecnológico, marcado pela proliferação de dispositivos móveis conectados a redes digitais de alta velocidade. O objetivo é propor uma nova abordagem teórica da cibercultura a partir da metáfora da "nuvem", mais adequada ao estudo de áreas emergentes como a "Internet das Coisas" e os processos de midiatização associados à comunicação móvel.

Palavras-chave: Ciberespaço; Nuvem; Cibercultura; Redes digitais; Dispositivos móveis.

* Doutorando em Ciências da Comunicação na Universidade da Beira Interior (Portugal) com bolsa da CAPES (Processo BEX 0852/13-9). Mestre em Comunicação Social pela UFMG. Contato: ivsatuf@gmail.com 
Abstract: The seminal notion of cyberspace present in the literary work of William Gibson focuses on the dichotomy connection/disconnection and the subsequent development of cyberculture studies helped to reinforce the separation between online (or virtual) and offline (or real). This article challenges the validity of this binary conception facing the current social and technological landscape, characterized by the proliferation of mobile devices connected to high-speed digital networks. The objective is to propose a new theoretical approach of cyberspace from the metaphor of the "cloud" most suitable to the study of emerging areas such as the "Internet of Things" and the mediatization processes associated with mobile communication.

Keywords: Cyberspace; Cloud; Cyberculture; Digital networks; Mobile devices.

Resumen: La noción inicial del ciberespacio presente en la obra literaria de William Gibson se centra en la dicotomía conexión/ desconexión y el desarrollo posterior de los estudios de cibercultura contribuyó a reforzar la separación entre online (o virtual) y offline (o real). Este artículo cuestiona la validez de esta concepción binaria frente al actual panorama social y tecnológico, que se caracteriza por la proliferación de dispositivos móviles conectados a redes digitales de alta velocidad. El objetivo es proponer un nuevo enfoque teórico del ciberespacio a partir de la metáfora de la "nube" más adecuada para el estudio de áreas emergentes como la "Internet de las Cosas" y los procesos de mediatización asociados a la comunicación móvil.

Palabras clave: Ciberespacio; Nube; Cibercultura; Redes digitales; Dispositivos móviles. 


\section{Introdução}

Transformações tecnológicas e sociais expandem constantemente os horizontes da cibercultura. Áreas emergentes como a Internet das Coisas e os processos de midiatização associados aos dispositivos móveis apresentam-se hoje como temáticas relevantes ao campo de estudo. Entretanto, objetos e problemas de pesquisa surgem frequentemente associados a novos vocabulários que se propagam rapidamente sem que haja maiores preocupações teóricas e reflexivas. Os últimos anos foram marcados pelo crescente uso metafórico do termo "nuvem" para descrever e analisar fenômenos sociotécnicos associados à mobilidade comunicacional, mas sua dimensão conceitual permanece pouco explorada.

Este artigo defende que "nuvem" não é um mero jargão tecnológico ou comercial, mas um conceito complexo que altera profundamente a noção clássica de ciberespaço fundada nos anos 1980 e que prevaleceu até o início do século XXI. O binômio conexão/desconexão do ciberespaço parece conflitante com um caráter etéreo e móvel da nuvem. Conforme explicam Lakoff e Johnson (1980), as metáforas vão muito além da dimensão diminuta das palavras, pois agem como elementos estruturantes do pensamento e da ação, ou seja, o ser humano não apenas se expressa por metáforas, mas também interpreta e experimenta o mundo metaforicamente. A partir desta abordagem são propostas duas questões centrais:

- A metáfora da nuvem é compatível com o tradicional conceito de ciberespaço?

- Como a reconfiguração metafórica age sobre objetos emergentes da cibercultura?

De forma resumida, pode-se dizer que metáforas são conjuntos de correspondência semântica entre dois domínios que inicialmente não possuem correlação direta. Quando a correspondência é estabelecida, surgem novas redes de significados que redefinem os limites cognitivos e as ações. O uso constante do recurso no cotidiano faz com que as associações semânticas sequer sejam notadas pelos interlocutores na maior parte das vezes. Para exemplificar a redefinição 
dos limites cognitivos, Lakoff e Johnson (1980) recorrem à trivial expressão "tempo é dinheiro". A temporalidade travestida em termos pecuniários permite tratar o decurso cronológico como mercadoria, um ativo transacionável como tantos outros, tornando corriqueiro o emprego de expressões como "Você está gastando meu tempo" ou "Eu investi muito tempo nela". O dinheiro funciona como metáfora estruturante ao associar ao tempo novas camadas semânticas que não existiam previamente.

$\mathrm{Na}$ ciência, as metáforas adquirem caráter epistêmico. Ao investigar as noções frequentemente associadas aos meios de comunicação, Meyrowitz (1993) mostra como pode ser bastante diferente analisar os meios como "canais" ou como "ambientes". A metáfora do canal associa todo meio de comunicação a um recipiente de transmissão cuja função é transportar o conteúdo de um ponto a outro, consequentemente, o meio em si perde importância na mesma proporção em que o conteúdo adquire relevância. A metáfora do canal leva a questões como "Quais os efeitos dos conteúdos?" ou “Como as várias audiências interpretam os conteúdos?”. Por outro lado, tratar os meios como ambientes desloca completamente a investigação, sendo necessário compreender como cada medium configura um ambiente particular e como os diversos ambientes midiáticos se relacionam. O conteúdo perde protagonismo e as características singulares dos meios assumem posição dominante, surgindo outras questões: "Como um novo meio altera os meios precedentes?" ou "Como as características de cada meio interagem com os códigos e costumes culturais?".

Parece válido sugerir que o mesmo deslocamento epistêmico ocorre na cibercultura. O objetivo deste artigo é compreender como a noção de nuvem atua como metáfora estruturante ao se sobrepor ao conceito básico de ciberespaço. A discussão é dividida em três partes. A primeira apresenta os momentos decisivos da evolução do conceito de ciberespaço, desde a origem na obra literária de William Gibson até a evolução do termo na pesquisa acadêmica. A segunda parte explora as raízes do conceito de nuvem aplicado à ciência da computação e destaca sua expansão para outros campos. A última parte discute a aplicação da metáfora da nuvem a duas áreas sensíveis à cibercultura contemporânea: a Internet das Coisas e a midiatização da vida cotidiana. 


\section{A metáfora do ciberespaço}

O neologismo ciberespaço surge uma única vez no romance de ficção científica "Burning Chrome", do escritor canadense William Gibson, publicado originalmente em 1982. Após essa brevíssima aparição, o termo se tornou recorrente na trilogia "The Sprawl", também conhecida como "trilogia do ciberespaço", composta pelos volumes "Neuromancer", "Count Zero" e "Mona Lisa Overdrive". Como será descrito adiante, a inspiração literária ultrapassou o campo ficcional e subsidiou, nos anos 1990, os trabalhos de intelectuais que ajudaram a estabelecer a cibercultura nas Ciências Humanas e Sociais.

O cenário futurista descrito por Gibson é povoado por tecnologias de conexão capazes de gerar representações gráficas a partir de imensos bancos de dados. A dimensão racional das máquinas se faz presente no prefixo "ciber", que remete ao controle e à automação aplicados aos sistemas informacionais, conforme a teoria cibernética de Norbert Wiener. Por outro lado, o ciberespaço é descrito em Neuromancer como "alucinação consensual" ("consensual hallucination") e "exultação incorpórea” (“bodiless exultation”), estabelecendo uma aparente contradição entre a racionalidade técnica e o estado de euforia sensorial provocado pela ambiência imaterial.

Os personagens são transportados para o ciberespaço através de eletrodos acoplados ao corpo, bastando pressionar um interruptor para fazer a transição. A dualidade conexão versus desconexão está ilustrada numa das muitas passagens em que a transição é descrita: "Molly já tinha ido embora quando ele retirou os eletrodos e o cômodo estava escuro. Verificou as horas. Estivera no ciberespaço por cinco horas"' (GIBSON, 1984, p. 52). O primeiro episódio da trilogia cinematográfica Matrix, lançado em 1999 e explicitamente inspirado na obra de William Gibson, apresenta uma cena muito semelhante quando Neo (Keanu Reeves), protagonista da trama, é colocado numa cadeira e tem um conector acoplado à parte de trás da cabeça. $\mathrm{O}$ dispositivo o conduz imediatamente para outra dimensão, o interior da "Matrix", onde Morpheus (Laurence Fishburne) o recebe num ambiente que é integralmente gerado por dados digitais. Assim, o ciberespaço age como metáfora estruturante da conexão digital a partir da qual deriva a concepção de "limite".

\footnotetext{
${ }^{1}$ Todas as citações presentes neste artigo extraídas de obras em língua inglesa foram traduzidas pelo autor a partir do original.
} 
$\mathrm{O}$ ato de se conectar ao ciberespaço sugere versões dos ritos de agregação e de separação, onde a tela do monitor possibilita a passagem a um outro mundo. A tela é a fronteira entre o individual e o coletivo, entre o orgânico e o artificial, entre o corpo e o espírito. O ciberespaço é o espaço simbólico onde se realizam, todos os dias, ritos de passagem do espaço físico e analógico ao espaço digital sem fronteiras. (LEMOS, 2004, p. 132)

Nesta sucinta descrição é possível verificar como a ideia de limite (ou fronteira) impõe uma série de dualismos: dentro e fora, on-line e off-line, real e virtual. A rede semântica gerada pela metáfora do ciberespaço teve enorme influência nas primeiras gerações de estudos da cibercultura que prosperou concomitante à popularização da World Wide Web (PAASONEN, 2012). Numa abordagem retrospectiva, Silver (2000) identifica três estágios no desenvolvimento do campo durante os anos 1990: 1) cibercultura popular; 2) estudos da cibercultura; 3) estudos críticos da cibercultura. Ainda que apresentem diferenças, todas as fases percebem o ciberespaço a partir dos limites e dos dualismos.

Jornalistas que cobriam tecnologia e early adopters ligados a setores high-tech ou a universidades foram os representantes da primeira etapa. As abordagens da "cibercultura popular" eram na maior parte das vezes meramente descritivas, havendo um misto de visões utópicas e distópicas. Foi nesta fase inicial que surgiu a expressão "autoestrada da informação" para se referir à internet. A metáfora reforçava características básicas do ciberespaço. Em primeiro lugar, havia uma outra dimensão para onde a mente era transportada, um lugar imaterial e dinâmico muito diferente daquele onde se encontrava o corpo inerte. Além disso, o recurso metafórico sugere velocidade, percurso, mapa, rota, direção e, numa era anterior à banda-larga, engarrafamento causado pela infraestrutura precária. Negroponte (1995, p. 18), um dos representantes da primeira fase de reflexões sobre a cibercultura, descreveu assim a novidade: "A autoestrada da informação trata do movimento global de bits sem peso à velocidade da luz". A aceleração vertiginosa da autoestrada estava em sintonia com a "alucinação consensual" e a "exultação incorpórea” do ciberespaço de Gibson.

A segunda etapa - "estudos da cibercultura" - agrega abordagens majoritariamente otimistas em relação ao ciberespaço, marcando a 
entrada definitiva da cibercultura no escopo da investigação acadêmica. Em duas obras icônicas, Rheingold (1993) e Turkle (1995) debatem, respectivamente, a reconfiguração das noções de comunidade e identidade no ciberespaço. Em vez de uma autoestrada onde cada um ocupa uma pista, a conexão conduz a ambientes de interação mediada por computador onde surgem laços de solidariedade e múltiplas identidades "virtuais". A linearidade da autoestrada é gradualmente ultrapassada pela metáfora da "navegação" para reforçar o caráter fluido e furtivo do ciberespaço. Mesmo que ainda seja possível falar de rotas e mapas, uma nova rede semântica altera a experiência da conexão. Ao contrário do motorista ávido por velocidade, o navegador precisa adotar um ritmo mais lento imposto por "ventos" e "marés" num enorme oceano que se desvela vagarosamente, o que favorece ações como a "caça" e a "pilhagem" de conteúdos (LÉVY, 1999).

A estruturação metafórica nesta segunda etapa se aproxima ainda mais da noção inicial de Gibson, segundo a qual o ciberespaço é um ambiente imaterial de projeção sensorial que desacopla mente e corpo. Um ponto comum nas reflexões é a explicitação total das interfaces, do limite entre o off-line e o on-line ou, conforme Johnson (2001, p. 39), do "espaço-tela em que era possível entrar". A passagem do mundo "real" para o "virtual" é tratada como um processo de imersão em que ocorre a "experiência de ser transportado para um lugar primorosamente simulado” (MURRAY, 2003, p. 102).

A terceira etapa - "estudos críticos da cibercultura" - promove abordagens mais complexas e adota uma postura cautelosa em relação ao ciberespaço. O olhar dos investigadores se desloca das interfaces tecnológicas (a tela do computador, os dispositivos de realidade aumentada) para a sociedade e a cultura num sentido mais amplo. Surge a preocupação com a segregação digital (digital divide) provocada tanto pela desigualdade econômica em escala planetária, quanto pela discriminação racial e de gênero. Questiona-se o ciberespaço como um ambiente aberto e ilimitado. Libicki (1997, p. 107) argumenta que todo sistema tecnológico cria três categorias - os outsiders, os usuários e os superusuários - e lança o alerta: "Metáforas, como armas carregadas, precisam ser usadas cautelosamente". O ciberespaço continua sendo concebido como uma dimensão paralela alheia ao mundo real, entretanto, é agora percebido com um lugar privilegiado cujo acesso é desigual. 
Desde a noção inicial de Gibson até os estudos críticos, a metáfora estruturante do ciberespaço organizou uma rede semântica que forjou a epistemologia da cibercultura, compreendida como "uma série de negociações que têm lugar tanto on-line quanto off-line" (SILVER, 2000 , p. 30). O ciberespaço parecia uma metáfora estruturante perfeitamente harmônica com um mundo no qual a conexão precisava da inércia do corpo diante de um computador e os tempos relativamente curtos de "imersão" contrastavam com os longos períodos de desconexão. A essência metafórica do ciberespaço é a contraposição entre a materialidade física e os ambientes simulados.

\section{A metáfora da nuvem}

Os estudos da cibercultura cresceram exponencialmente no início do século XXI amparados por uma série de novas plataformas on-line. A Wikipédia foi criada em 2001 e logo alcançou o posto de ícone da cultura colaborativa digital. A "cibersocialidade" representava o avanço natural das reflexões sobre comunidades virtuais. As investigações acerca das identidades on-line também prosperaram com o lançamento, em 2003, do Second Self, plataforma de imersão que apresentava um universo paralelo povoado por avatares. O ciberespaço ainda era a metáfora dominante, entretanto, mudanças tecnológicas e sociais significativas começavam a alterar o panorama da cibercultura. Castells et al. (2007) destacam que foi justamente em 2003 que o número de telefones celulares ativos ultrapassou o total de linhas fixas em escala global. Os anos seguintes foram marcados pela acelerada expansão das redes de alta velocidade (3G) e pela emergência de dispositivos móveis dotados de capacidade computacional: os smartphones.

O computador deixava de ser a única interface de conexão na mesma proporção em que as redes digitais passavam a acompanhar a mobilidade dos corpos. A melhoria constante das infraestruturas de telecomunicação alterou gradualmente a percepção de tempo e espaço que até então caracterizava a conexão digital. Dispositivos móveis como smartphones e tablets, ao contrário dos computadores, são tecnologias "always-on" (BARON, 2008; TURKLE, 2011) que recebem e enviam dados mesmo quando não estão em uso direto pelo usuário. Alertas noticiosos chegam a qualquer momento, sensores 
de geolocalização indicam a posição exata do usuário e aplicativos de mensagem instantânea criam conexões a partir das demandas interativas. Basta pressionar a pequena tela táctil para imediatamente se conectar à rede, nada dos eletrodos da ficção científica de William Gibson nem dos cabos ou dos hardwares fixos que dominavam os rituais de passagem para o ciberespaço.

O acelerado processo de integração dos dispositivos móveis ao tecido social (LING, 2012) foi acompanhado pelo emprego crescente da metáfora da nuvem para descrever a conexão digital. Mosco (2014) afirma que a expressão "cloud computing" já era usada nos anos 1990 por especialistas em informática para descrever cenários futuristas, porém, apenas em meados da década seguinte tornou-se conhecida pelo público leigo, quando a conexão móvel à internet se tornou realidade. Grandes companhias do setor digital como Google, Apple e Amazon passaram a recorrer à expressão para se referir a um sistema de conexão ubíqua que permitia o acesso a documentos e softwares diretamente da rede, sem necessidade de armazenamento na memória dos aparelhos pessoais. A popularização de produtos e serviços como Dropbox e Netflix ajudou a consolidar a lógica da computação em nuvem: a informação digital está acessível em qualquer lugar, a todo momento e a partir de múltiplos dispositivos de conexão.

A nova metáfora constrói uma rede semântica muito diferente daquela associada ao ciberespaço. A nuvem não se apresenta como barreira nem interface através da qual o usuário é transportado de um lugar para outro. Ela "paira" permanentemente sobre os inúmeros pontos errantes interconectados e "respinga" informação no fluxo da vida ordinária. A nuvem se adapta perfeitamente às ações de download e upload que, segundo a teoria de Lakoff e Johnson (1980), podem ser caracterizadas como "metáforas de orientação". O intenso fluxo de "baixar" e "subir" informação ubíqua em formato digital é o que marca a sociedade atual, não o constante "entrar" e "sair" de um universo paralelo. Enquanto o ciberespaço conduz a um ambiente imersivo e simulado, a nuvem não conduz a lugar nenhum, ela é que envolve o usuário onde quer que ele esteja. Quando a conexão se torna banal a ponto de criar a sensação coletiva de conectividade permanente, a ideia de limite e suas dualidades - dentro/fora, real/virtual, on-line/off-line - tende a perder força ou até mesmo desaparecer.

O filme Her, lançado em 2013, é uma das melhores represen- 
tações ficcionais da metáfora da nuvem. A trama se concentra na relação afetiva entre Theodore Twombly (Joaquin Phoenix) e um programa de computador, representado somente pela voz da atriz Scarlett Johansson. O software-amante atende pelo nome de Samantha e acompanha o usuário-companheiro durante todo o dia, sempre disponível nos mais diversos dispositivos permanentemente associados à nuvem. Theodore Twombly não ultrapassa fronteiras para se encontrar com Samantha. A relação ocorre em espaços ordinários: a cozinha, o escritório, a rua. A hiperconexão é ininterrupta e móvel, dispersa no fluxo cotidiano, bem diferente da imagem do corpo de Neo fixo em uma cadeira enquanto sua mente experimentava temporariamente o ciberespaço (ou a Matrix).

Portanto, não existe um outro espaço acessado por mecanismos de teletransporte, mas o espaço-tempo da experiência, o dia a dia reconfigurado por uma trama digital evolvente, o que torna cada vez mais difícil compreender a cibercultura contemporânea pela lente dualista do ciberespaço. É preciso redefinir os limites cognitivos para atuar no que Lemos (2011, p. 22) chama de "cultura da mobilidade" na qual "os novos nômades virtuais criam territorializações em meio a movimentos no espaço urbano". Tal concepção reordena a cibercultura ao demonstrar que não há mais um espaço "virtual" projetado para além do "real", as famosas concepções do ciberespaço como "autoestrada informacional” ou "oceano navegável”. O que existe é a "virtualização" de territórios criados e experimentados num aqui e agora hiperconectado.

A nuvem se apresenta como metáfora para pensar e agir num mundo cada vez mais dependente de linguagens computacionais e algoritmos, o que Manovich (2013) denomina de "cultura do software". Ainda que possa soar contraditório, o software em constante disponibilidade na nuvem torna o hardware - a princípio sólido e imutável - cada vez mais "poroso". O smartphone pode se transformar rapidamente em bússola ou mapa pela interconexão com satélite e sensores de movimento (acelerômetro e giroscópio). Os pequenos ícones que representam os aplicativos na tela do aparelho, tais como as nuvens, são entidades etéreas em permanente "flutuação" que se moldam à materialidade e a transformam pelo fluxo de dados. A nuvem facilita a compreensão da surpreendente flexibilidade do hardware quando "envolto" por softwares ubíquos. 
Há, entretanto, outra dimensão fundamental na nova metáfora, pois ela permite integrar o digital com a natureza. A nuvem é um elemento natural constituído pela condensação de minúsculas partículas de água em suspensão na atmosfera e, quando se torna metáfora, estimula uma abordagem orgânica das relações. Por outro lado, o ciberespaço é o "lugar-máquina” (ELIAS, 2007) instituído a partir da ligação entre o orgânico e o inorgânico. É importante retomar a análise de Lakoff e Johnson (1980) para compreender como as metáforas que usamos rotineiramente ultrapassam a dimensão linguageira para governar o pensamento e a ação. Agir no ciberespaço é interagir com máquinas que projetam a sensorialidade para uma outra dimensão, enquanto agir na nuvem significa incorporar o digital ao cotidiano, conectar entidades orgânicas. São duas concepções muito distintas e que produzem resultados díspares na investigação científica.

\section{A cibercultura nas nuvens}

As duas seções anteriores dirigem-se à primeira questão proposta no início do texto: A metáfora da nuvem é compatível com o tradicional conceito de ciberespaço? A argumentação teórica e os exemplos convocados sustentam uma resposta negativa. Há uma série de divergências entre a nuvem e o ciberespaço, uma incompatibilidade de princípios, constatação que leva à segunda pergunta: Como a reconfiguração metafórica age sobre objetos emergentes da cibercultura? Essa é uma questão muito ampla, pois se dirige à vastidão de temas e problemas de um campo de estudos multifacetado. Portanto, neste artigo, são abordados de maneira muito breve apenas dois objetos caros à cibercultura: a "Internet das Coisas" e os processos de midiatização associados à comunicação móvel.

A Internet das Coisas - ou Internet of Things, no termo originalmente cunhado em língua inglesa - é a integração dos objetos aos sistemas digitais de comunicação por meio de infraestruturas tecnológicas de leitura e transmissão de dados digitais (CHAOUCHI, 2010; COSTA, 2013). Seu uso mais comum está associado a pequenos sensores de identificação de radiofrequência, conhecidos como etiquetas RFID, que permitem a qualquer objeto interagir com o ambiente (próximo e distante) pelo constate recebimento e envio 
de informação de e para outros objetos. A primeira precaução para evitar equívocos teóricos é compreender o significado de "coisa" presente na denominação do objeto de estudo. Coisa no sentido empregado pode ser considerado, de fato, qualquer coisa: eletrodomésticos, plantas, toras de madeira, roupas, animais (inclusive seres humanos), etc. Na nuvem tudo se torna "conectável" e os objetos ganham funções infocomunicacionais pela capacidade de agir e reagir consoante o contexto (LEMOS, 2013).

Tentar ajustar a metáfora do ciberespaço para estudar a Internet das Coisas é um esforço ao mesmo tempo inútil e improdutivo. Mais uma vez cabe ressaltar que o recurso metafórico não é uma simples escolha entre as muitas palavras disponíveis no dicionário ou mesmo na elaboração de neologismos, o que seria observado como um recurso meramente estilístico. A metáfora é uma escolha cognitiva que influencia a forma de pensar e de agir. Quando objetos se comunicam com outros objetos pela interconexão digital generalizada, a cibercultura está diante de uma rede de associações híbridas tão porosas, etéreas, móveis, suspensas e envolventes quanto as nuvens.

Não somos levados a um deslocamento, a uma desmaterialização do mundo, a uma matriz virtualmente deslocada do mundo concreto das coisas. Não vamos ao espaço cibernético e às "não-coisas" eletrônicas, mas sim a lugares concretos e aos objetos que os ocupam. A rede digital é, cada vez mais, uma rede que está sendo acoplada a todos os nossos objetos e lugares do quotidiano. (LEMOS, 2013, p. 245)

O deslocamento epistemológico é nítido. A cibercultura hoje não é o fenômeno resultante do "espaço-ciber" separado por interfaces que demarcam a transposição, mas a cultura que deriva de um "espaço-nuvem" em que todas as coisas do mundo são passíveis de integração digital. Esta concepção sugere a importância da metáfora para outra área relevante de investigação: a midiatização da vida cotidiana (DEUZE, 2012; HEPP, 2013; HOLANDA, 2015). Esta corrente de pesquisa se concentra nos processos de transformação da experiência (individual e coletiva) resultantes de mudanças ocorridas simultaneamente nas tecnologias de comunicação e nas práticas socioculturais.

A midiatização ajusta o olhar sobre os pontos de interseção, o entrelaçamento entre as mais diversas formas de interações que in- 
fluenciam as interações. Smartphones e tablets ganham proeminência justamente porque são vetores ativos na reconfiguração da experiência. Numa abordagem radical da midiatização, Deuze (2012) defende que as pessoas não vivem mais "com" a mídia, mas "na" mídia, sendo possível identificar padrões emergentes de comportamento em qualquer ambiente cosmopolita:

Vagando pelas ruas de Amsterdam, Johanesburgo e Los Angeles, não se pode deixar de testemunhar a vida midiática em todos os lugares. A maneira como as pessoas se movem através do espaço público enquanto vestem ou empunham meios de comunicação privados (como telefones móveis, câmeras digitais e players portáteis de música). (...) Exploradores que navegam a selva urbana passando de hotspot para hotspot - em cafés, bibliotecas públicas, estandes de venda, saguões de hotel. Motoristas interagindo com sistemas de navegação pessoal por voz, as crianças no banco de trás dividindo sua atenção entre as imagens da cidade que passam zunindo e um filme executado em telas acopladas ao banco da frente. (DEUZE, 2012, p. 2)

O filme Her, já mencionado no tópico anterior, consegue captar com acuidade a midiatização da vida cotidiana ao demonstrar as interações por meio de uma panóplia de dispositivos de conexão. A vida midiática (media life) seria então a única forma possível de existência devido à impossibilidade de promover o afastamento das tecnologias de interconexão. Não existe um "lado de fora" ou um "outro lado", como leva a crer a metáfora do ciberespaço. Viver na mídia equivale a estar envolto em um fluxo constante de dados digitais sempre disponíveis, uma nuvem carregada, densa e multiforme.

A metáfora da nuvem pode e deve ser estendida a outros objetos pertinentes ao campo de estudos da cibercultura, como as mídias locativas (GORDON; SOUZA E SILVA, 2011) e os wearables devices (PELLANDA, 2014). Ambos possuem pontos de tangência com a Internet das Coisas e a midiatização da vida cotidiana, como fica evidente nas citações apresentadas acima, embora sejam áreas com especificidades que sugerem tratamento diferenciado na investigação acadêmica. Qualquer que seja o objeto de estudo, o que importa é evitar a simplificação dicotômica do ciberespaço para analisar os fenômenos atuais. 


\section{Considerações finais}

Compreender a metáfora como mecanismo estruturador da cognição é importante para o desenvolvimento científico. No caso específico da cibercultura a questão se torna ainda mais relevante, visto que a área se constituiu a partir de um conceito-metáfora: o ciberespaço. Entretanto, este artigo argumenta sobre sua inadequação para analisar objetos contemporâneos, principalmente aqueles que se impõem pela mobilidade e ubiquidade comunicacional. A nuvem derivada da "cloud computing" se impõe como metáfora essencial para pensar e agir num mundo hiperconectado. Portanto, a mudança da metáfora aponta para questões epistemológicas fundamentais para o desenvolvimento da cibercultura.

Entretanto, a nuvem traz consigo alguns riscos não abordados neste artigo e que sugerem uma série de tópicos para investigações futuras. Há alguns pontos controversos, como o suposto "apagamento" das interfaces em prol da conexão. Deuze (2012, p. 185), por exemplo, advoga a invisibilidade da dimensão física das tecnologias "dentro de interfaces naturais, o sumiço de usos concretos pela convergência e portabilidade, sua evaporação como infraestrutura das interações cotidianas". A nuvem cria condições cognitivas para a "evaporação" dos dispositivos de conexão, conduzindo a questões fundamentais: Existe mediação tecnológica sem interface? Quais as consequências comunicacionais das interfaces "invisíveis"? Como observou Jorge Luís Borges no conto "O jardim dos caminhos que se bifurcam”, escolher uma entre duas ou mais opções impõe a automática eliminação de futuros possíveis relacionados às escolhas não realizadas. Que futuros possíveis são eclipsados pela metáfora da nuvem? Quais metáforas são rejeitadas em favor da concepção vigente? Estas questões ajudam a evitar um uso ingênuo das metáforas estruturantes.

Há, ainda, um segundo nível relacionado às escolhas. Mesmo no interior da rede semântica convocada pela metáfora eleita há muitas outras escolhas subsequentes que destacam alguns aspectos e ocultam outros (LAKOFF; JOHNSON, 1980). Este artigo pode conduzir à falsa impressão de que as noções associadas à nuvem conduzem a um cenário sempre positivo. $\mathrm{O}$ que a nuvem revela é tão importante quanto aquilo que ela esconde. Como destaca Mosco (2014), 
existe também uma "dark cloud" que gera diversos distúrbios, entre os quais o elevado nível de degradação do meio-ambiente devido ao consumo extremo de energia para garantir o funcionamento ininterrupto dos gigantescos servidores que garantem o funcionamento da nuvem. Existe, também, a polêmica sobre a privacidade gerada por um mundo que transforma tudo em dados, inclusive informações pessoais. Portanto, este artigo se apresenta como uma pequena contribuição para o campo de estudos da cibercultura e, ao mesmo tempo, pretende servir como ponto de partida para a exploração de uma metáfora emergente.

\section{REFERENNCIAS}

BARON, Naomi. Always on: language in an online and mobile world. Oxford: Oxford University Press, 2008.

CASTELLS, Manuel et al. Mobile communication and society: a global perspective. Cambridge: MIT Press, 2007.

CHAOUCHI, Hakima. Introduction to the Internet of Things. In: CHAOUCHI, Hakima (Ed.). The Internet of things: connecting objects to the web. London/Hoboken: ISTE-Wiley. 2010, p. 1-33.

COSTA, Francis da. Rethinking the Internet of Things: a scalable approach to connecting everything. New York: Apress Media, 2013.

DEUZE, Mark. Media life. Cambridge: Polity, 2012.

ELIAS, Herlander. Néon digital: um discurso sobre os ciberespaços. Covilhã: Livros LabCom, 2007.

GIBSON, William. Neuromancer. New York: Ace Books, 1984.

GORDON, Eric; SOUZA E SILVA, Adriana. Net locality: why location matters in a networked world. Chichester: Wiley-Blackwell, 2011.

HEPP, Andreas. The communicative figurations of mediatized worlds: mediatization research in times of the 'mediation of everything. European 
Journal of Communication, v. 28, n. 6, p. 615-629, 2013.

HOLANDA, André. Apontamentos para uma teoria da vida midiatizada. In: 24 Encontro Nacional da Compós, Brasília, 2015. Anais eletrônicos... 2015. Disponível em: <http://www.compos.org.br/biblioteca/compos-201520699834-cb48-4742-82b3-76cce7e22a1d\%282\%29_2741.pdf>. Acesso em: 08 set. 2015.

JOHNSON, Steven. Cultura da interface: como o computador transforma nossa maneira de criar e comunicar. Rio de Janeiro: Jorge Zahar Editor, 2001.

LAKOFF, George; JOHNSON, Mark. Metaphors we live by. Chicago: University of Chicago Press, 1980.

LEMOS, André. Cibercultura, tecnologia e vida social na cultura contemporânea. Porto Alegre: Sulina, 2004.

LEMOS, André. Cultura da mobilidade. In: BEIGUELMAN, Giselle; LA FERLA, Jorge (Orgs.). Nomadismos tecnológicos. São Paulo: Editora Senac, 2011. p. 15-43.

LEMOS, André. A comunicação das coisas: teoria ator-rede e cibercultura. São Paulo: Annablume, 2013.

LÉVY, Pierre. Cibercultura. São Paulo: Ed. 34, 1999.

LIBICKI, Martin. Defending cyberspace and other metaphors. Washington, DC: National Defense University, 1997.

LING, Richard. Taken for grantedness: the embedding of mobile communication into society. Cambridge: MIT Press, 2012.

MANOVICH, Lev. Software takes command. New York: Bloomsbury, 2013.

MEYROWITZ, Joshua. Images of media: Hidden ferment—and harmonyin the field. Journal of Communication, v. 43, n. 3, p. 55-66, 1993. 
MOSCO, Vincent. To the cloud: big data in a turbulent world. Boulder: Paradigm Publishers, 2014.

MURRAY, Janet. Hamlet no holodeck: o futuro da narrativa no ciberespaço. São Paulo: Itaú Cultural: Unesp, 2003.

NEGROPONTE, Nicholas. Being digial. London: Hodder \& Stoughton, 1995.

PAASONEN, Susanna. What cyberspace? Traveling concepts in Internet Research. In: GOGGIN, Gerard; MCLELLAND, Mark (Eds.). Internationalizing Internet Studies beyond anglophone paradigms. New York: Routledge, 2012. p. 18-31.

PELLANDA, Eduardo. Protestos pela ótica do Google Glass: uma análise das potencialidades de amplificação da vigilância do cidadão. Liinc em Revista, v. 10, n. 1, 2014.

RHEINGOLD, Howard. The virtual community: homesteading on the electronic frontier. Cambridge: MIT press, 1993.

SILVER, David. Looking backwards, looking forwards: cyberculture studies 1990-2000. In: GAUNTLETT, David (Ed.). Web.Studies: Rewiring media studies for the digital age. 2000, p. 19-30.

TURKLE, Sherry. Life on the screen: identity in the age of the internet. New York: Simon \& Schuster, 1995.

TURKLE, Sherry. Alone together: Why we expect more from technology and less from each other. New York: Basic books, 2011. 
AÇÃO MIDIÁTICA, n.11. Jan/jun. 2016. Curitiba. PPGCOM-UFPR. ISSN 2238-0701

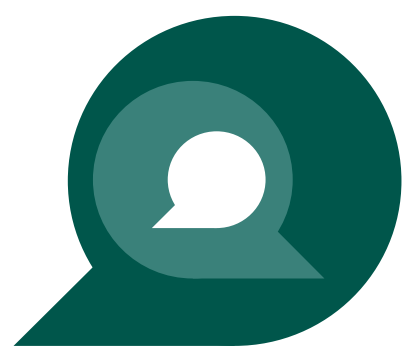

